\title{
The Linguistic Characteristics of KPG Written Mediation Tasks across Proficiency Levels
}

\author{
Maria Stathopoulou \\ National and Kapodistrian University of Athens \\ mastathop@enl.uoa.gr
}

\begin{abstract}
Concerned with written mediation performance of Greek speakers of English when they relay information from one language to another, this paper aims at systematically analyzing and describing mediation tasks included in the national exams for foreign language proficiency, known as Kratiko Pistopiitiko Glossomathias (henceforth KPG). The questions it addresses are: what differentiates mediation tasks across proficiency levels and what language is likely to be produced by candidates of different levels. It ultimately presents a set of illustrative descriptors relevant to mediation which define the language to be used at each level.
\end{abstract}

\section{Introduction}

This paper presents the results derived from the systematic analysis and description of KPG written mediation tasks which require the simultaneous use of two linguistic systems with the purpose of relaying messages from one language to another in written communication. ${ }^{1}$ The analysis has been conducted with a view to investigating what linguistic features differentiate KPG written mediation tasks across proficiency levels and what language is likely to be produced by candidates of different levels. ${ }^{2}$

$\mathbf{1}$ The KPG exams measure candidates' competence in comprehending and producing oral and written discourse as well as their ability to act as mediators across languages. Find KPG mediation tasks and information about KPG exams at http://rcel.enl.uoa.gr/kpg.

$\mathbf{2}$ This study is part of a large-scale research for the purposes of my PhD thesis which investigated what mediation strategies lead to successful mediation performance.

\section{(cc) BY-NC-ND}


Although mediation has been included in the Common European Framework of Reference for Languages (henceforth CEFR) (Council of Europe 2001) and has been considered as an ability users of a given language should possess so that they can participate in today's multicultural contexts, it has not received as much attention as the activities of reception, production and interaction. Given that no benchmarked illustrative scales for the mediatory use of language are available therein (cf. Alderson 2007, Little 2007, North 2007), the particular language activity has seldom been included in foreign language curricula until recently ${ }^{3}$ and its investigation remains at an embryonic level. ${ }^{4}$ Taking into consideration this gap and in response to the need for further investigation, the present study constitutes a first step towards the development of illustrative descriptors relevant to mediation for each proficiency level drawing data from the KPG examination system, the only examination system in Europe which assesses mediation performance. ${ }^{5}$ Actually, these 'can-do' statements, which have been derived from the systematic examination of the linguistic characteristics of mediation tasks included in the national exams for language proficiency, specify what mediators of different levels are likely to be able to do with the language and ultimately enable us to decide through what types of written tasks mediation competence can be developed and measured at each level.

For the purposes of this particular study, the description of the mediation tasks across levels of proficiency has been based upon a specific model which has resulted from a Task Analysis Project being carried out by the Research Centre for Language Teaching, Testing and Assessment (henceforth RCeL), University of Athens. Actually, the aim of this project was to design a model for the linguistic description of the texts for comprehension and the texts to be produced in the exams, so as to tabulate their lexicogrammatical generically defined features and hence create a kind of exam 'linguistic syllabus' of each exam level across the KPG languages (English, French, German, Italian). ${ }^{6}$ Specifically,

3 In Greece, the newly developed National Curriculum for Foreign Languages actually includes illustrative descriptors for the mediatory use of language, which are empirically developed and are partly based on the task-analysis results presented in this paper (see Dendrinos and Stathopoulou 2012).

4 See, for instance, Stathopoulou (2009) who has attempted to investigate the extent to which the source (Greek) text regulates the target text resulting in the production of hybrid or (Greenglish) formations.

5 Mediation performance is measured at B1, B2 and C1 level of proficiency. At lower levels -A1 and A2- KPG exams involve mediation only at the level of comprehension rather than the level of production.

6 Working at the RCeL as a research assistant gave me the opportunity to have access to the KPG Task Analysis Database, which has been constructed for the purposes of the task analysis project. For further information, see http://www.rcel.enl.uoa.gr/research/ language-education-research/the-task-analysis-project.html 
written mediation tasks have been described on the basis of a pre-defined set of task features, namely, the Topic of the text (e.g., environment, technology), its discourse environment (e.g., magazine, newspaper), its text-type (e.g., e-mail, announcement) identified in terms of the communicative goal it may achieve (e.g., to inform, to advise,), its generic process (e.g. description, narration, explanation, argumentation, instruction), and the communicative roles or identities of the addressor and addressee. Although each of the aforementioned parameters is discrete and distinct in its own right, they all contribute to the overall meaning of a given text interacting and affecting one another in critical ways.

Drawing on Systemic Functional Linguistics (SFL) (Halliday and Hasan 1985, Halliday and Matthiessen 1999, 2004) and the approach to language study developed by Knapp and Watkins (2005), the basic categories of analysis presented above echo the socially-situated view of language and reflect a view of texts as the "material form of language" (ibid: 18) which are generated in specific social situations and are constructed with specific purposes by the writer (see Kondyli and Lykou 2009). The model, in other words, echoes the genre based approach to designing and assessing writing tasks, ${ }^{7}$ the one KPG exams adopt in the testing of language and builds upon an understanding that the production of language largely depends on the context of situation in which it is used.

\section{Mediation and Mediation Tasks}

According to Dendrinos (2006), mediation is understood as the process whereby a user of a certain language (the mediator) extracts certain messages from a verbal or visual, spoken or written text of any type in one language, code or dialect and relays them in another so as to achieve a certain communicative goal. In this paper, mediation is regarded as social practice which occurs in order to facilitate communication between parties not sharing the same language. ${ }^{8}$ The mediator acts as an intermediary between cultures and languages giving "a voice to those who have lost it" (Zarate et al. 2004: 57). Actually, the practice of mediation is considered to be an important aspect of human intercultural communication as in our everyday life we may frequently assume the role of mediator in many different domains of activity. Being able to cope with multiple intercultural

7 See what genre-based approaches to teaching and assessment involve in Cope and Kalantzis 1993, Hyland 2004, 2007, Knapp and Watkins 2005.

8 The particular study deals with the interlinguistic mediation (rather than intralinguistic), which involves the relaying of information from one language to another for a given communicative purpose. 
experiences and mediate effectively by explaining messages expressed in one language into the other seems to be a prerequisite for individuals' successful participation in today's multilingual societies.

Mediation as a term became known in the ELT field when it was introduced in the CEFR in 2001. It is defined therein as a process where "the language user is not concerned to express his/her own meanings, but simply to act as an intermediary between interlocutors who are unable to understand each other directly-normally (but not exclusively) speakers of different languages" (Council of Europe 2001: 87-88). ${ }^{9}$ Using the CEFR as a basic reference and recognizing the crucial role of mediation in today's societies which demand cultural and linguistic negotiation, the KPG examination battery assesses candidates' written and oral mediation performance through mediation tasks which require candidates to select pertinent information from the source text and use it to convey a message in the target language.

In the KPG writing test paper, which concerns us presently, B1, B2 and C1 level candidates are required to produce a text in the target language by using only the relevant source information on the basis of the required context of situation (i.e. what the purpose of the text is, who the addressor and addressee are, in what discourse environment the text to be produced is to appear, etc.). ${ }^{10}$ They are, actually, expected to compose a socially-meaningful text in the target language which may convey the main idea of the Greek text, make a summary of it or relay only some messages contained in the Greek text.

More specifically, the $B 1$ level mediation activity requires candidates to compile bits of information from one or from an assortment of Greek texts, such as a thematic page of a popular magazine, a travel leaflet, etc., and to produce one single text of about 80 words in English. ${ }^{11}$ The Greek text(s) are short and are likely to have factual information. The English text is most often to be of a different type and to have a different communicative purpose than the target text. The amount of information that candidates must relay in English is rather limited.

9 While the CEFR (Council of Europe 2001) regards mediation as a process of mere transferring of meanings, this study sharply distinguishes mediation from translation, as the latter is a highly specialized activity which concerns professionals whose main goal is to transfer as closely as possible meanings included in a text of a given language to another (cf. Federici 2007, Risku 2002). The mediator's task, on the contrary, is not limited to mere transferring of all s/he hears or reads, but s/he has to select which messages from the original text(s) will be relayed into the target text (on the basis of what might be relevant to the new context of situation).

10 Note that candidates aiming for B1 or B2 sit for an intergraded exam, the writing test of which contains two activities for each level, or four in total.

11 For a detailed presentation of the different requirements of mediation tasks across levels, see Dendrinos and Stathopoulou (2010). 
The $B 2$ level mediation activity requires candidates to select information from a Greek text and to produce one text in English of about 100 words in order to achieve a communicative purpose. The source texts used at this exam level are of a greater variety than at B1 level, and they are slightly more complex. What is more, whereas the $B 1$ level mediation activity offers flexibility as to the amount of information to be relayed, the B2 level mediation activity requires transference of a greater amount of information from the source text. Nevertheless the B2 level candidate can use some avoidance strategies and ultimately select what to say on the basis of what s/he knows how to say in English.

The $C 1$ level mediation activity requires more careful reading of the Greek text so that candidates can relay specific information from the source into a target text in English in about 200 words. At this particular level, the mediation task obliges candidates to stick more closely to the source text and relay specific pieces of information rather than select those items they can write about in the target language. Length and sophistication also differentiate B2 and C1 level source texts employed for the mediation activities.

\section{Data and Procedure}

For the purposes of this study, I analyzed thirty two (32) written mediation tasks designed for fourteen (14) examination periods for the B2 level, seven (7) for the $\mathrm{B} 1$ and twelve (11) for the $\mathrm{C}^{12}$ on the basis of a pre-determined set of task features, as already mentioned in the Introduction. In order to draw conclusions, I have adopted a top-down or deductive approach to data-analysis as it has been based on a pre-determined model with specific categories of analysis (e.g., task features) (see Thomas 2006).

The analysis of the written mediation tasks was facilitated by means of an electronic database constructed at the RCeL for the investigation of the task requirements of the different exam modules. To briefly refer to the characteristics of the database, the tasks included therein have been stored for each exam period and proficiency level. The database also contains information about the type of task (e.g., multiple choice, gap filling, free writing, etc.) and what each task measures (e.g., comprehension or production) along with information about the texts related to a given task (e.g., texts for comprehension and texts to be produced). Each task and text has been described in terms of specific features

12 I started with the examination period of May 2007 for B1, November 2003 for B2 and April 2005 for C1. The last tasks analyzed are those of the period of November 2010. Not all levels were introduced at the same examination period (e.g., B1 was firstly administered in May 2007) that is why the sampling does not concern the same examination periods. 
(e.g., topic, discourse environment, text-type, text-process, etc). Each task feature may take different values which are specified in pre-defined typologies, e.g., the KPG typologies of topics, discourse environments, text-types, text-processes, etc.

The meta-data ${ }^{13}$ collected from the database which was actually related only to the written mediation tasks, was later quantified and presented in tables and charts as shown in the following section. This quantification of the data made comparisons across levels easier and ultimately contributed to a better understanding of what parameters differentiate KPG written mediation tasks.

\section{Presentation and Discussion of Findings}

\subsection{What Differentiates Mediation Tasks across Proficiency Levels?}

Regarding the linguistic category of topic, task description and analysis reveals that the higher the level, the more sophisticated topics seem to appear requiring the use of more elevated vocabulary.

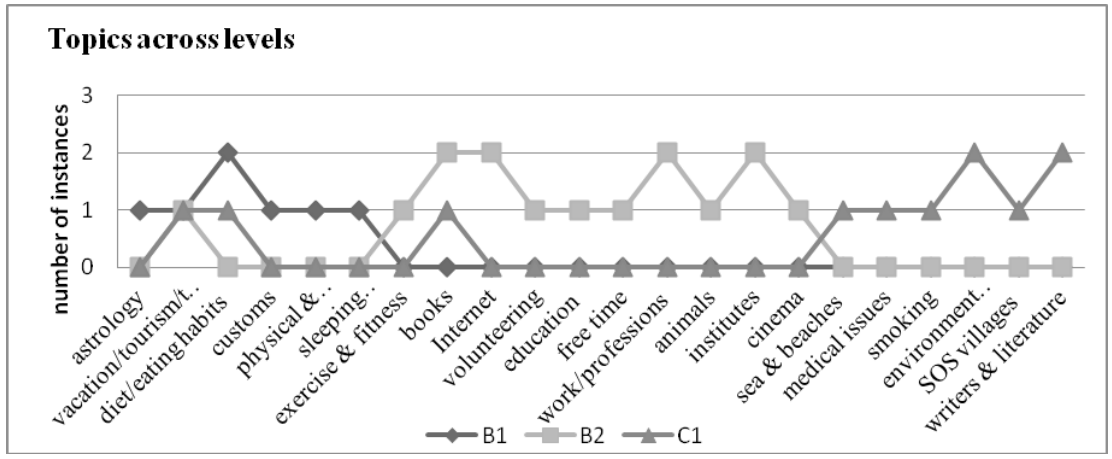

Chart 1. Topics across levels

Specifically, B1 level candidates need to have the language to handle personal and daily life topics (such as eating habits, health) which have relevance to the needs of children or teenagers as this is the predominant age span of

13 The term meta-data is used to refer to the 'data about data' and contains information about the content, source, quality and other characteristics of a particular text (source or target in our case), which constitutes the data (see Adolphs 2006 for a comprehensive definition). 
the population taking the particular test (see Chart 1). While the topics which feature at B2 level are more of general interest related to the candidates' everyday life (e.g., exercise and fitness, Internet, education, free time etc), at C1 level candidates are expected to deal with more specialized, abstract and less everyday issues (e.g., medical issues, SOS villages, literature). The step up to C1 seems to involve dealing with lexicogrammatically challenging topics, such as the environment, in a sense that they require the use of more sophisticated vocabulary as opposed to the lexis required at lower levels.

In relation to the text types candidates are asked to produce at each level, data analysis has demonstrated that there is a manifest progression from B1 to C1 level, as shown in Table 1.

Table 1.

Text-types across levels

\begin{tabular}{|l|c|c|c|c|c|c|}
\hline & \multicolumn{2}{|c|}{ B1 } & \multicolumn{2}{c|}{ B2 } & \multicolumn{2}{c|}{ C1 } \\
\hline & Count & $\%$ & Count & $\%$ & Count & $\%$ \\
\hline email & 7 & 100 & 3 & 21,43 & 0 & 0 \\
\hline announcement & 0 & 0 & 1 & 7,14 & 1 & 9,09 \\
\hline report & 0 & 0 & 2 & 14,29 & 2 & 18,18 \\
\hline article & 0 & 0 & 1 & 7,14 & 0 & 0,00 \\
\hline postcard & 0 & 0 & 1 & 7,14 & 0 & 0,00 \\
\hline letter & 0 & 0 & 0 & 0,00 & 3 & 27,27 \\
\hline website presentation & 0 & 0 & 1 & 7,14 & 0 & 0,00 \\
\hline book presentation & 0 & 0 & 2 & 14,29 & 1 & 9,09 \\
\hline film presentation & 0 & 0 & 1 & 7,14 & 0 & 0,00 \\
\hline text for an informative/promotional leaflet & 0 & 0 & 1 & 7,14 & 2 & 18,18 \\
\hline text for a university prospectus & 0 & 0 & 0 & 0,00 & 1 & 9,09 \\
\hline text in a magazine column & 0 & 0 & 1 & 7,14 & 0 & 0,00 \\
\hline written text to be presented orally & 0 & 0 & 0 & 0,00 & 1 & 9,09 \\
\hline Sum & 7 & & 14 & & 11 & \\
\hline
\end{tabular}

Specifically, it is shown that B1 level mediation tasks always require the production of e-mail messages. The most frequent text-type at B2 level mediation tasks is also the e-mail message but at a lower frequency (see Table 1). Interestingly enough, emails do not appear in C1 level mediation tasks. Along with e-mails, B2 mediation tasks frequently require candidates to produce reports, the percentage of which increases in $\mathrm{C} 1$ level mediation tasks. Finally, 
as the table above clearly shows, candidates are asked to produce letters only in the $\mathrm{C} 1$ level writing test.

As regards the generic processes of the texts to be produced, there is no clear distinction across levels (see Table 2). It could be, though, maintained that variety is what discriminates $\mathrm{C} 1$ from B1 and B2 level tasks. Irrespectively of the performance level, the most frequent generic process is description. While at B1 level description is frequently combined with explanation, B2 and C1 level candidates are mostly asked to produce texts that only describe. Across levels, narration and explanation are the only two generic processes that only appear in combination with description.

Table 2

Generic processes across levels

\begin{tabular}{|l|c|c|c|c|c|c|}
\hline \multirow{2}{*}{ Target generic process } & \multicolumn{2}{|c|}{ B1 } & \multicolumn{2}{c|}{ B2 } & \multicolumn{2}{c|}{ C1 } \\
\cline { 2 - 7 } & Count & $\%$ & Count & $\%$ & Count & $\%$ \\
\hline describe & 0 & 0,0 & 6 & 42,9 & 4 & 36,4 \\
\hline instruct & 2 & 28,6 & 2 & 14,3 & 1 & 9,1 \\
\hline argue & 0 & 0,0 & 1,0 & 7,1 & 0 & 0,0 \\
\hline describe \& explain & 2 & 28,6 & 2 & 14,3 & 3 & 27,3 \\
\hline describe \& instruct & 2 & 28,6 & 1 & 7,1 & 0 & 0,0 \\
\hline describe \& narrate & 0 & 0,0 & 1 & 7,1 & 1 & 9,1 \\
\hline describe \& argue & 0 & 0,0 & 0 & 0,0 & 2 & 18,2 \\
\hline instruct \& explain & 0 & 0,0 & 1 & 7,1 & 0 & 0,0 \\
\hline explain \& argue & 1,0 & 14,3 & 0 & 0,0 & 0 & 0,0 \\
\hline
\end{tabular}

It is also of great relevance to discuss what text-types are associated with what generic processes at each level, as in our model of analysis text-type and generic process define 'genre' and consequently the language to be used (see Table 3).

Table 3.

Text types in combination with generic processes at B1 level

\begin{tabular}{|l|l|c|c|}
\hline \multirow{2}{*}{ Text-type } & \multirow{2}{*}{ Generic process } & \multicolumn{2}{|c|}{ B1 } \\
\cline { 3 - 4 } & & Count & \% \\
\hline email & describe \& explain & 2 & 28,6 \\
\hline email & instruct & 2 & 28,6 \\
\hline email & describe \& instruct & 2 & 28,6 \\
\hline email & explain \& argue & 1 & 14,3 \\
\hline Sum & & 7 & \\
\hline
\end{tabular}


At $B 2$ level, there can be found different types of combinations between text types and generic processes without a single pattern being emerged. Slightly increased is the percentage of those book presentations which describe (see Table 4).

Table 4.

Text types in combination with generic processes at B2 level

\begin{tabular}{|l|l|c|c|}
\hline \multirow{2}{*}{ Text-type } & \multirow{2}{*}{ Generic process } & \multicolumn{2}{|c|}{ B2 } \\
\cline { 2 - 4 } & & Count & $\%$ \\
\hline email & argue & 1 & 7,1 \\
\hline email & instruct & 1 & 7,1 \\
\hline email & describe \& instruct & 1 & 7,1 \\
\hline text in a magazine column & instruct \& explain & 1 & 7,1 \\
\hline text in an informative leaflet & instruct & 1 & 7,1 \\
\hline announcement & describe & 1 & 7,1 \\
\hline report & describe & 1 & 7,1 \\
\hline report & describe \& explain & 2 & 7,1 \\
\hline book presentation & describe & 1 & 7,1 \\
\hline website presentation & describe & 1 & 7,1 \\
\hline postcard & describe & 1 & 7,1 \\
\hline film presentation & describe & 1 & 7,1 \\
\hline article & describe \& explain & 1 & \\
\hline Sum & & 1 & \\
\hline & & 1 & 7 \\
\hline
\end{tabular}

At $\mathrm{C} 1$ level, the most frequent combinations are letters which describe and argue and reports which describe and explain (see Table 5).

The discourse environments at B2 and $C_{1}$ levels are increasingly diverse requiring the production of texts with more complex structures and a broader spectrum of lexis. As demonstrated in Chart 2, at B1 level, there is only one discourse environment that appears and this is related to the personal domain (e.g., interaction with his/her family or friends about their everyday activities). At B2 level, candidates are frequently asked to produce language not only in their interpersonal encounters (or personal domain) but also in the linguistic environment of a magazine or a leaflet. The newspaper, as a discourse environment, appears more frequently at $\mathrm{C} 1$ level. 
Major Trends in Theoretical and Applied Linguistics

Table 5.

Text types in combination with generic processes at $\mathrm{C} 1$ level

\begin{tabular}{|l|l|c|c|}
\hline \multirow{2}{*}{ Text-type } & \multirow{2}{*}{ Generic process } & \multicolumn{2}{|c|}{ C1 } \\
\cline { 2 - 4 } & & Count & describe \& narrate \\
\hline letter & describe \& argue & 2 & 18,2 \\
\hline letter & instruct & 1 & 9,1 \\
\hline text in an informative leaflet & describe & 1 & 9,1 \\
\hline announcement & describe & 1 & 9,1 \\
\hline book blurb & describe & 1 & 9,1 \\
\hline university prospectus & describe & 2 & 9,1 \\
\hline written presentation to be read & describe \& explain & 1 & 9,1 \\
\hline report & describe \& explain & 11 & \\
\hline text in a promotional leaflet & & & 18,2 \\
\hline Sum & & & 1 \\
\hline
\end{tabular}

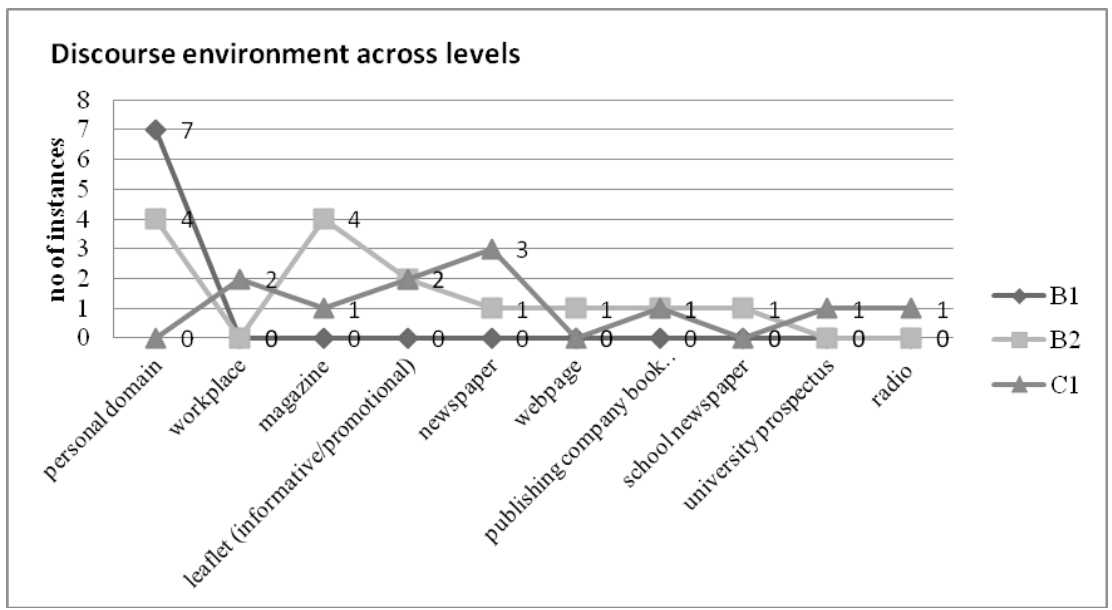

Chart 2. Discourse environments across levels

With reference to task purpose, there is some progression from B1 to C1 as the possibility of having to deal with a greater variety of purposes appears from B2 level upwards (see Chart 3). 


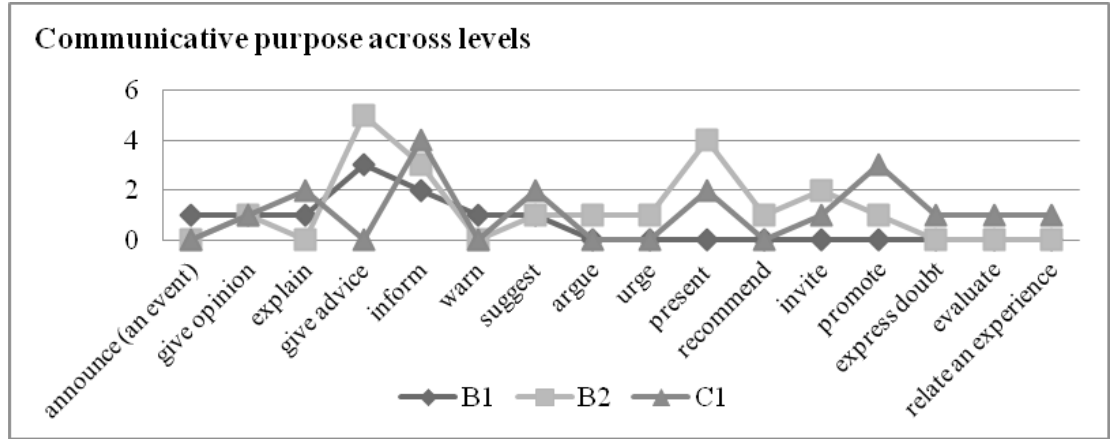

Chart 3. Communicative purpose across levels

Actually, B1 level tasks which usually give advice, announce, express their opinion and explain (see Chart 3 ) seem to require the use of simple language. What distinguishes B2 and C1 level tasks does not seem to be the variety in communicative purposes but the types of communicative purposes the tasks of each level require. Put differently, communicative goals which require the use of more complex syntactical structures (i.e., sentences), elaborated use of connectives to maintain logical relations and link points, and sophisticated vocabulary mainly appear at C1 level. Expressing doubt, promoting, evaluating are some of these.

The final linguistic parameter explored is related to the communicative roles assumed by the participants in the communicative event. It seems that there is a gradual progression through the levels from 'personally known ${ }^{14}$ (friends) to specified audiences (magazine or newspaper readers, editors, customers, tourists etc) (see Table 6). The only role relationship occurring at B1 level is between friends while $\mathrm{B} 2$ and $\mathrm{C} 1$ level tasks address a broader range of audiences.

14 Describing writing tests and particularly referring to writer-reader relationships, Shaw and Weir (2007: 249) use the expression 'personally known audience' to refer to the relationship between people familiar to each other (usually friends and family). 
Table 6.

Communicative roles across levels

\begin{tabular}{|c|c|c|c|}
\hline \multirow{2}{*}{ Addressor } & \multirow{2}{*}{ Addressee } & \multicolumn{2}{|c|}{ C1 } \\
\hline & & Count & $\%$ \\
\hline \multirow[t]{2}{*}{ friend } & friend & 7 & 100 \\
\hline & & \multicolumn{2}{|c|}{$\mathrm{C} 2$} \\
\hline friend & friend & 4 & 28,57 \\
\hline company member & book catalogue reader & 1 & 7,14 \\
\hline writer of a promotional text for a leaflet & promotional leaflet reader & 1 & 7,14 \\
\hline writer of a webpage text & Internet user/webpage reader & 1 & 7,14 \\
\hline magazine text writer & magazine reader & 2 & 14,29 \\
\hline pupil & pupil & 1 & 7,14 \\
\hline writer of a report & young people & 1 & 7,14 \\
\hline magazine text writer & young people & 1 & 7,14 \\
\hline private company owner & customer & 1 & 7,14 \\
\hline \multirow[t]{2}{*}{ magazine/newspaper text writer } & tourists/travellers & 1 & 7,14 \\
\hline & & \multicolumn{2}{|c|}{ C1 } \\
\hline radio show presenter & audience of a radio programme & 1 & 9,09 \\
\hline writer of a informative text for a leaflet & informative leaflet reader & 1 & 9,09 \\
\hline reader of a magazine column & magazine reader & 1 & 9,09 \\
\hline publishing company & book reader & 1 & 9,09 \\
\hline newspaper text writer & newspaper reader & 1 & 9,09 \\
\hline newspaper editor & newspaper reader & 1 & 9,09 \\
\hline newspaper editor & student & 1 & 9,09 \\
\hline organization member & organization member & 1 & 9,09 \\
\hline company & customer & 1 & 9,09 \\
\hline organization manager & organization member & 1 & 9,09 \\
\hline university & student & 1 & 9,09 \\
\hline
\end{tabular}




\subsection{What Mediation Tasks are Appropriate for Each Proficiency Level?}

Task description of mediation tasks has led us to understand what differentiates mediation tasks across levels in terms of their linguistic characteristics and ultimately what mediators of different levels are likely to do with the language. The resulting illustrative descriptors below define the language to be used which actually varies according to the conditions under which communication takes place (context of situation) and ultimately help decide which tasks with what requirements are appropriate for each proficiency level.

Specifically, the B1 level learner/ candidate is likely to

$\square$ relay information about topics of everyday life,

$\square$ produce texts of a familiar text-type fulfilling a limited number of generic processes which require the use of simple and basic language,

$\square$ produce texts of the personal domain,

$\square$ perform some basic communicative acts which entail selection of simple lexicogrammnatical structures and

$\square$ address only 'personally known' audiences

In general, the B1 level learner or candidate is expected to be familiar with some basic generic conventions and use simple language and text organization. The style of the target text $\mathrm{s} / \mathrm{he}$ is expected to be able to produce should be informal and personal.

The B2 level learner/ candidate is likely to

$\square$ relay information about topics of general interest related to their everyday life,

$\square$ produce texts of various types which may fulfill multiple generic processes which require the use of rather simple language,

$\checkmark$ produce texts appearing in different discourse environments,

$\square$ perform a greater variability of communicative acts demanding higher level of language competence and

$\square$ address different audiences.

Overall, the B2 level learner or candidate should know what structural features differentiate a variety of genres and use simple language. Additionally, s/he is expected to be able to produce both semi-formal and informal texts with personal or less personal tone.

The C1 level learner/ candidate is likely to

relay information about more specialized, sophisticated and abstract topics, $\checkmark$ produce texts of a wide range of types fulfilling generic processes which require the use of complex lexicosyntactical structures, 
produce texts appearing in different discourse environments,

perform a wide range of communicative acts which require the use of complex language (e.g., argue) and

$\square$ address a wide range of audiences.

Actually, C1 level language users are expected to be able to use complex language in a wide variety of discourse environments producing texts whose style is mainly formal and impersonal.

In relation to the topic areas language users of the different levels are to handle, these should be adequately close to their needs and interests so that those of a given performance level have sufficient existing schemata that will enable them to respond to the requirements of the task.

\section{Conclusions and Implications for Teaching and Testing}

The present paper has constituted an attempt to describe the linguistic features of those KPG tasks which assess language users' ability to perform as mediators on the basis of a predefined set of parameters which reflect a socially-situated view of language. The outcome of such an analysis, which contributed to conclusions about what differentiates mediation tasks across levels, has been the development of a set of illustrative descriptors which determine the language that is likely to be produced by mediators.

To summarize the main findings, the systematic analysis of mediation tasks in terms of their linguistic features has shown that the degree of candidates' familiarity with the topics and how abstract these are is one of the factors that seem to distinguish mediation tasks across levels. Actually, it can be claimed that the higher the level the higher the degree of abstractness. In addition, it has been indicated that the higher the level, the greater the genre variability. That means that learners or candidates of lower levels are likely to produce a limited range of text-types when mediating while $\mathrm{C} 1$ level candidates are expected to be able to produce a wide variety of text-types. Discourse environment variability is also what differentiates tasks. As a matter of fact, those requiring the use of complex language should appear in mediation tasks of higher levels. Moreover, communicative stress rises with the level. C1 candidates, for instance, should be able to achieve communicative goals which demand use of highly complex language. Finally, the relationship between addressor and addressee is what makes a task more or less demanding.

Referring to the implications of this study, the illustrative descriptors relevant to mediation provided herein may help test designers and item-writers to decide 
what mediation tasks to design for each level and what aspects of language competence to measure. They can actually be used as templates for developing test tasks and constitute a basis for syllabus sequencing. In the long run, the particular descriptors may assist washback from the test to teaching and test preparation and reverse washback of teaching into the test-craft process (see also Davidson and Lynch 1994). In fact, they may function as a blueprint for the teacher who wishes to prepare his/her students for the particular exams and may constitute a basis for the design of material aiming at the development of learners' mediation skills.

\section{Acknowledgements}

I am deeply grateful to Prof. B. Dendrinos, director of the RCeL, for including me in the RCeL team and for providing me with invaluable guidance and support at every step of the research project. My special thanks also go to Dr Kia Karavas for her valuable comments that helped me improve the content of this paper. I also wish to thank Moira Hill, member of the RCeL staff, who edited an earlier version of this paper. 


\section{References}

Adolphs, S. 2006. Introducing Electronic Text Analysis: A practical Guide for Language and Literary Studies. London and New York: Routledge.

Alderson, C. 2007. The CEFR and the need for more research. The Modern Language Journal 91(4): 659-663.

Cope, B. and M. Kalantzis (eds.). 1993. The powers of literacy: A genre approach to teaching writing. Pittsburgh, PA: University of Pittsburgh Press.

Council of Europe. 2001. Common European Framework of Reference for Languages: Learning, teaching, assessment. Cambridge: Cambridge University Press.

Davidson, F. and B.K. Lynch, 2002. Testcraft: A Teacher's Guide to Writing and Using Language Test Specifications. New Haven and London: Yale University Press.

Dendrinos, B. 2006. Mediation in Communication, Language Teaching and Testing. Journal of Applied Linguistics 22: 9-35.

Dendrinos, B. and M. Stathopoulou. 2010. Mediation activities: Cross-Language Communication Performance. ELT News, KPG Corner, 249: 12. Retrieved 20 August 2011 from: http://rcel.enl.uoa.gr/kpg/kpgcorner_may2010.htm

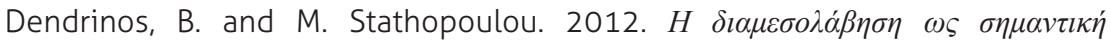

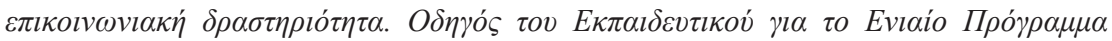

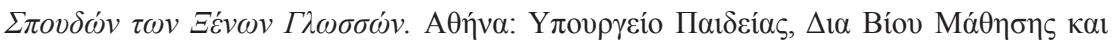

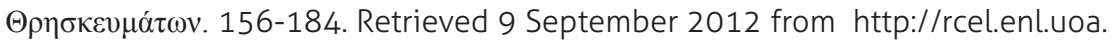
gr/xenesglosses/docs/O $\Delta$ НГО $\% 20$ EKПАI $\Delta$ EYTIKOY.pdf

Federici, E. 2007. The translator's intertextual baggage. Forum for Modern Language Studies 43(2): 147-160. 
Halliday, M.A.K. and R. Hasan. 1985. Language, Context and Text: Aspects of Language in a Social-semiotic Perspective. Oxford: Oxford University Press.

Halliday, M.A.K. and C.M.I.M. Matthiessen. 1999. Construing experience through meaning. London, New York: Continuum.

Halliday, M.A.K. and C.M.I.M. Matthiessen. (3rd ed.). 2004. An Introduction to Functional Grammar. London \& NY: Arnold.

Hyland, K. 2004. Genre and second language writing. Ann Arbor, MI: University of Michigan Press

Hyland, K. 2007. Genre pedagogy: Language, literacy and L2 writing instruction. Journal of Second Language Writing 16: 148-164.

Knapp, P. and M. Watkins. 2005. Genre, Text, Grammar: technologies for teaching and assessing writing. Sydney: University of South Wales Press.

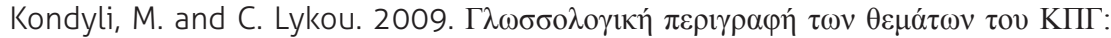

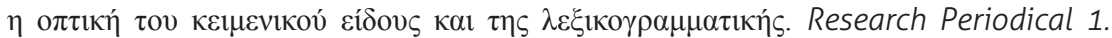
Research Centre for Language Teaching, Testing and Assessment. Retrieved 20 September 2011 from http://rcel.enl.uoa.gr/periodical/index_en.htm

Little, D. 2007. The Common European Framework of Reference for Languages: Perspectives on the Making of Supranational Language Education Policy. The Modern Language Journal 91(4): 645-653.

North, B. 2007. The CEFR Illustrative descriptor scales. The Modern Language Journal 91(4): 656-659.

Risku, H. 2002. Situatedness in Translation Studies. Cognitive Systems Research 3: 523-533.

Shaw, S.D. and C.J. Weir. 2007. Examining Writing in a Second Language, Studies in Language Testing 26. Cambridge: Cambridge University Press and Cambridge ESOL.

Stathopoulou, M. 2009. Written mediation in the KPG exams: Source text regulation resulting in hybrid formations. Unpublished dissertation submitted for the MA degree in the Applied Linguistics Postgraduate Programme, Faculty of English Language and Literature. National and Kapodistrian University of Athens, Greece. Retrieved 9 September 2012 from http://rcel.enl.uoa.gr/kpg/ma-stathopoulou.htm 
Major Trends in Theoretical and Applied Linguistics

Thomas, D.R. 2006. A General Inductive Approach for Analyzing Qualitative Evaluation Data. American Journal of Evaluation 27: 237-246.

Zarate, G., A. Gohard-Radenkovic, D. Lussier, H. Penz. 2004. Cultural mediation in language learning and teaching. Kapfenberg: European Centre for Modern Languages/ Council of Europe Publishing. 